\title{
Skin Photosensitivity
}

National Cancer Institute

\section{Source}

National Cancer Institute. Skin Photosensitivity. NCI Thesaurus. Code C38004.

Increased sensitivity of the skin to light exposure. 